Claude Guérin Armand R. J. Girbes

\section{Improved ICU outcomes in ARDS patients: implication on long-term outcomes}

Received: 9 December 2013

Accepted: 17 December 2013

Published online: 17 January 2014

(C) Springer-Verlag Berlin Heidelberg and ESICM 2014

\section{Guérin $(\bowtie)$}

Service de Réanimation Médicale, Hôpital de la Croix-Rousse, 103 Grande Rue de la Croix-Rousse, 69004 Lyon, France

e-mail: claude.guerin@chu-lyon.fr

Tel.: +33-4-26109418

Fax: +33-4-72071774

\section{A. R. J. Girbes}

Department of Intensive Care, VUmc,

Amsterdam, The Netherlands

The primary goal of intensive care medicine is to prevent short-term mortality by developing innovative and efficient interventions. This task has been achieved in many clinical conditions, one of which is ARDS. The ARDS network [1] showed that using lower tidal volume increases survival. More recently, a short course of neuromuscular blocking agents [2] and the use of prone position [3] have been proven to significantly improve survival in ARDS patients with severity criteria. As the practice of intensive care medicine has reached high levels of efficiency, caregivers and researchers have recently turned their efforts towards the assessment of the long-term outcomes of the patient, beyond the ICU discharge. As an example, it was found in ARDS patients surviving the ICU stay that the physical, but not the mental, quality of life decreased in the very long term [4]. In patients with acute kidney injury requiring (AKI) hemodialysis during the hospital stay as compared to patients without AKI, the long-term (up to 10 years) mortality was not different but the dialysis requirement for end-stage kidney disease was considerably increased [5]. The implications of not dying in the ICU on longterm outcomes are schematically drawn in Fig. 1.

Wang et al. [6] re-analyzed the data of a prospective large cohort of early acute respiratory distress syndrome (ARDS) patients and found that 1-year mortality was clinically significantly higher than short-term mortality, i.e. at hospital discharge, and largely depended on previous comorbidities and age, but not on severity of the acute illness. The fact that mortality increases as time is running and age is going up is a basic tenet in epidemiology; eventually, all patients die. The fact that acute illness severity was not a marker of long-term mortality is not surprising because these indicators were originally developed to predict hospital mortality. Using them for predicting long-term outcome is not validated, and subject for further research. Actually, as Wang et al. split their study into two epochs, the rate of mortality was similar across them, $24 \%$ from ICU admission to hospital discharge and $22 \%$ from hospital discharge to 1-year after ICU admission. The finding that previous comorbidities affect long-term mortality in ARDS is not unexpected but quite new and clinically relevant. Indeed, in the most recent RCT on ARDS [2, 3, 7], patients with preexisting conditions with expected death within 6-12 months were excluded. However, it is known that prior quality of life in patients admitted to ICU is lower than in the general population [8], and that this worst preexisting health status impacts on long-term survival in acute kidney injury [9].

The common decision-making to accept a patient into an ICU precludes taking into account patient's age, comorbidities, and functional status, including ADL. However, at the time a patient is referred to the ICU, the diagnosis of ARDS has usually not yet been made. Furthermore, the assessment of ARDS 12-24 h after the initial diagnosis may be highly relevant to start interventions with important benefits [3] and to define a more 
Fig. 1 Patient's trajectory after ICU discharge alive

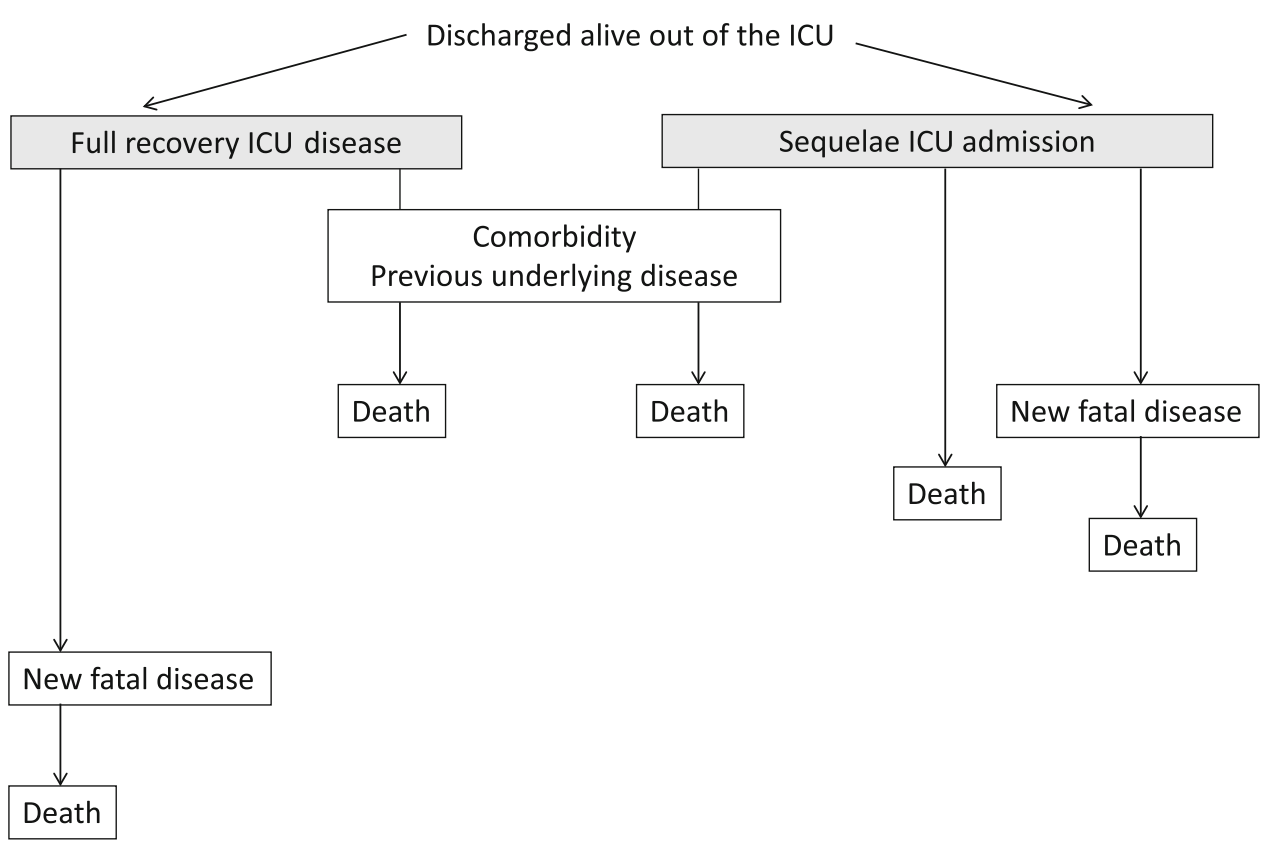

reliable prognosis [10]. Therefore, should age and comorbidities play a role in end-of-life decisions in patients with ARDS, this could be done after a few days of management and not at the time of ICU admission. Thus, age and comorbidities associated with ARDS cannot easily be used to decide on the eventual futility of an ICU admission. Wang et al. tell us, however, that age and comorbidities influence the long-term prognosis in ARDS. Should this finding then be used to set the level of care during the ICU stay? It may be difficult for a clinician to cope with such a long-term perspective if the patient becomes stabilized and/or some improvement in the acute illness can be anticipated, and the given evidence-based treatment improves short-term survival. In cancer patients, several recent reports have shown that the short-term outcome was improved when early interventions were carried out [11]. Pène et al. [12] have found that, in patients with hematological malignancies admitted with multiple organ failure, the short-term mortality does not depend on previous health status. Azoulay et al. [13] recently made a comprehensive and relevant summary for the policy regarding ICU admission in patients with serious underlying disease. The main message of this review is to not restrict ICU admission to patients with cancer and hematological malignancies, and by contrast to admit those patients as early as possible into the ICU. Whether this policy should also apply to patients with cancer or hematological malignancies and ARDS remains to be established. Treatment of ARDS will not cure the underlying disease and severe co-morbidities. But it is of value to know that the treatment of ARDS is so successful that it allows patients to die-at a later stage-of their underlying or original disease. Adding time to life, even months, can be of high value. In this respect, noninvasive ventilation is of value in patients with acute respiratory failure, who have declined intubation [14], leading to the concept of palliative noninvasive ventilation [15].

The findings from the study by Wang et al. should encourage better defining and assessing of previous comorbidities in a way that could be relevant for the ICU. The burden of comorbidity is commonly assessed by using the Charlson's approach or global scores like APACHE III or SAPS III. The Charlson index is very important but has been validated over a 10-year followup. Such a long-term follow-up may be irrelevant for patients discharged alive after an ICU stay. Furthermore, it has been developed more than a quarter of a century ago. The relative importance of each component should henceforth be updated. Global scores like SAPS III include age, physiology, severity of the acute illness, and comorbidity. Therefore, entering age, comorbidity score, and global score together into a multivariate analysis would promote multicollinearity. Finally, any specific comorbidity can be better described. As an example, COPD can be more precisely defined from the GOLD classification. Chronic kidney disease can be staged according to the baseline glomerular filtration rate. HIV infection can be staged into three clinical categories and three levels of CD4 count.

The study of Wang et al. performed a sensitivity analysis based upon the recent Berlin proposal for ARDS [16]. They found that, to meet the Berlin criteria for ARDS, $14.7 \%$ of ARDS patients had to be excluded, a rate which is close to what we found in a recent prospective survey [17]. ARDS is a syndrome, not a disease. The experts apparently did not incorporate into the Berlin definition the fundamental pathophysiological impairments, such as higher extra-vascular lung water, higher 
lung permeability, lung recruitability, and size of the "baby lung". We are left with ARDS severity staged from the intensity of hypoxemia taking into account the level of PEEP, used as a threshold and not at a fixed value. The results by Wang et al. provide us with an additional puzzle piece to understand the heterogeneity in outcome of ARDS patients. This kind of information is easier to implement than its pathophysiological counterpart. In line with COPD phenotypes [18], phenotyping ARDS taking into account comorbidities could be a way to better understand and to better manage ARDS patients and to reduce the heterogeneity in this syndrome.

The findings by Wang et al. stress the need of further larger multicenter surveys, specifically addressing the issue of defining comorbidity.

Conflicts of interest No author declares any conflict of interest.

\section{References}

1. ARDSnet (2000) Ventilation with lower tidal volumes as compared with traditional tidal volumes for acute lung injury and the acute respiratory distress syndrome. The Acute Respiratory Distress Syndrome Network. N Engl J Med 342:1301-1308

2. Papazian L, Forel J, Gacouin A, PenotRagon C, Perrin G, Loundou A, Jaber S, Arnal J, Perez D, Seghboyan J (2010) ACURASYS Study Investigators. Neuromuscular blockers in early acute respiratory distress syndrome. N Engl J Med 363:1107-1116

3. Guerin C, Reignier J, Richard JC, Beuret P, Gacouin A, Boulain T, Mercier E, Badet M, Mercat A, Baudin O, Clavel M, Chatellier D, Jaber S, Rosselli S, Mancebo J, Sirodot M, Hilbert G, Bengler C, Richecoeur J, Gainnier M, Bayle F, Bourdin G, Leray V, Girard R, Baboi L, Ayzac L, Group PS (2013) Prone positioning in severe acute respiratory distress syndrome. N Engl J Med 368:2159-2168

4. Herridge MS, Tansey CM, Matte A, Tomlinson G, Diaz-Granados N, Cooper A, Guest CB, Mazer CD, Mehta S, Stewart TE, Kudlow P, Cook D, Slutsky AS, Cheung AM, Canadian Critical Care Trials G (2011) Functional disability 5 years after acute respiratory distress syndrome. N Engl J Med 364:1293-1304

5. Wald R, Quinn RR, Luo J, Li P, Scales DC, Mamdani MM, Ray JG, University of Toronto Acute Kidney Injury Research G (2009) Chronic dialysis and death among survivors of acute kidney injury requiring dialysis. JAMA 302:1179-1185

6. Wang CY, Calfee CS, Paul DW, Janz DR, May AK, Zhuo H, Bernard GR, Matthay MA, Ware LB, Kangelaris KN (2013) One-year mortality and predictors of death among hospital survivors of acute respiratory distress syndrome. Intensive Care Med. doi:10.1007/s00134-013-3186-3
7. Ferguson ND, Cook DJ, Guyatt GH, Mehta S, Hand L, Austin P, Zhou Q, Matte A, Walter SD, Lamontagne F, Granton JT, Arabi YM, Arroliga AC, Stewart TE, Slutsky AS, Meade MO, OT Investigators, Canadian Critical Care Trials G (2013) High-frequency oscillation in early acute respiratory distress syndrome. N Engl J Med 368:795-805

8. Wehler M, Geise A, Hadzionerovic D, Aljukic E, Reulbach U, Hahn EG, Strauss R (2003) Health-related quality of life of patients with multiple organ dysfunction: individual changes and comparison with normative population. Crit Care Med 31:1094-1101

9. Hofhuis JG, van Stel HF, Schrijvers AJ, Rommes JH, Spronk PE (2013) The effect of acute kidney injury on longterm health-related quality of life: a prospective follow-up study. Crit Care 17:R17

10. Villar J, Perez-Mendez L, Blanco J, Anon JM, Blanch L, Belda J, SantosBouza A, Fernandez RL, Kacmarek RM, Spanish Initiative for Epidemiology S, Therapies for AN (2013) A universal definition of ARDS: the $\mathrm{PaO} 2 / \mathrm{FiO} 2$ ratio under a standard ventilatory setting - a prospective, multicenter validation study. Intensive Care Med 39:583-592

11. Fuchs L, Chronaki CE, Park S, Novack V, Baumfeld Y, Scott D, McLennan S, Talmor D, Celi L (2012) ICU admission characteristics and mortality rates among elderly and very elderly patients. Intensive Care Med 38:1654-1661

12. Pene F, Soares M (2008) Can we still refuse ICU admission of patients with hematological malignancies? Intensive Care Med 34:790-792

13. Azoulay E, Soares M, Darmon M, Benoit D, Pastores S, Afessa B (2011) Intensive care of the cancer patient: recent achievements and remaining challenges. Ann Intensive Care 1:5
14. Azoulay E, Kouatchet A, Jaber S, Lambert J, Meziani F, Schmidt M, Schnell D, Mortaza S, Conseil M, Tchenio X, Herbecq P, Andrivet P, Guerot E, Lafabrie A, Perbet S, Camous L, Janssen-Langenstein R, Collet F, Messika J, Legriel S, Fabre X, Guisset O, Touati S, Kilani S, Alves M, Mercat A, Similowski T, Papazian L, Meert AP, Chevret S, Schlemmer B, Brochard L, Demoule A (2013) Noninvasive mechanical ventilation in patients having declined tracheal intubation. Intensive Care Med 39:292-301

15. Azoulay E, Demoule A, Jaber S, Kouatchet A, Meert AP, Papazian L, Brochard L (2011) Palliative noninvasive ventilation in patients with acute respiratory failure. Intensive Care Med 37:1250-1257

16. Ranieri VM, Rubenfeld GD, Thompson BT, Fergsuon ND, Cladwell E, Fan E, Camporota L, Slutsky AS (2012) Acute respiratory distress syndrome. The Berlin definition. JAMA 307:E1-E8

17. Hernu R, Wallet F, Thiolliere F, Martin O, Richard JC, Schmitt Z, Wallon G, Delannoy B, Rimmele T, Demaret C, Magnin C, Vallin H, Lepape A, Baboi L, Argaud L, Piriou V, Allaouchiche B, Aubrun F, Bastien O, Lehot JJ, Ayzac L, Guerin C (2013) An attempt to validate the modification of the AmericanEuropean consensus definition of acute lung injury/acute respiratory distress syndrome by the Berlin definition in a university hospital. Intensive Care Med 39:2161-2170

18. Han MK, Agusti A, Calverley PM, Celli BR, Criner G, Curtis JL, Fabbri LM, Goldin JG, Jones PW, Macnee W, Make BJ, Rabe KF, Rennard SI, Sciurba FC, Silverman EK, Vestbo J, Washko GR, Wouters EF, Martinez FJ (2010) Chronic obstructive pulmonary disease phenotypes: the future of COPD. Am J Respir Crit Care Med 182:598-604 